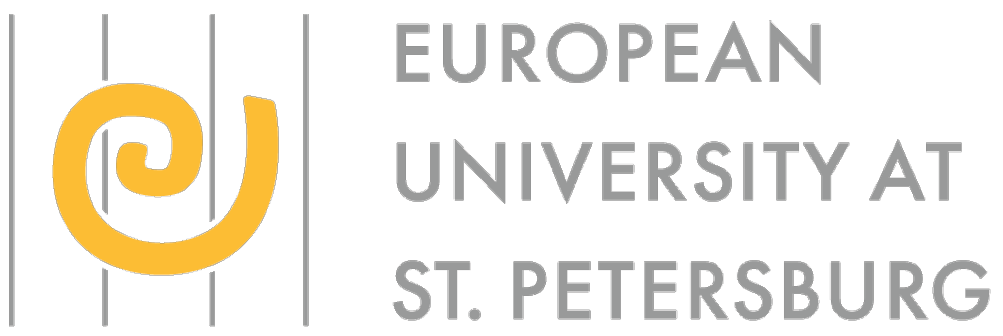

\title{
Health Capital Provision and Human Capital Accumulation
}

by Leonid V. Azarnert

$2020 / 02$

Working Paper Series

Department of Economics

European University at St. Petersburg 
Azarnert L. (2020) Health Capital Provision and Human Capital Accumulation European University at St. Petersburg, Department of Economics, Working Paper 2020/02, 28 p.

\begin{abstract}
This article analyzes the effect of public policy intervention in the production of health capital on fertility, private investment in children's health and education and human capital accumulation. I have used a growth model with endogenous fertility, in which the usual parental trade-off between the quantity and quality of their children is augmented with an additional factor that affects children's human capital, which is health. I analyze the overall society-wide effect of public policy intervention and derive a condition that determines precisely whether public provision of free health services increases or decreases the average level of human capital in the society.
\end{abstract}

Keywords: Fertility, Health capital, Human capital, Growth

JEL classification: D30, I12, J10, J13, J24, O10, O40

\title{
Leonid Azarnert,
}

National Research University Higher School of Economics, St Petersburg, Russia; CESifo, Munich, Germany.

$\bowtie \quad$ Leonid.Azarnert@gmail.com

(C) L. Azarnert, 2020 


\title{
Health Capital Provision and Human Capital Accumulation"
}

\author{
Leonid V. Azarnert ${ }^{*}$ \\ Department of Economics, National Research University Higher School of Economics, St \\ Petersburg, 194100, Russia; CESifo, Munich, Germany
}

\begin{abstract}
This article analyzes the effect of public policy intervention in the production of health capital on fertility, private investment in children's health and education and human capital accumulation. I have used a growth model with endogenous fertility, in which the usual parental trade-off between the quantity and quality of their children is augmented with an additional factor that affects children's human capital, which is health. I analyze the overall society-wide effect of public policy intervention and derive a condition that determines precisely whether public provision of free health services increases or decreases the average level of human capital in the society.
\end{abstract}

Keywords: fertility, health capital, human capital, growth

JEL classification: D30, I12, J10, J13, J24, O10, O40

\footnotetext{
" I would like to thank Robert Tamura and two anonymous referees for valuable suggestions. I also thank Kirill Borissov, Dierk Herzer and participants at the $5^{\text {th }}$ International Workshop on Economic Growth, Environment and Natural Resources (St. Petersburg 2019), the Annual International Conference of the Research Group on Development Economics (Berlin 2019), the $24^{\text {th }}$ conference on Dynamics, Economic Growth, and International Trade, DEGIT-XXIV (Odense 2019), and the 2020 Annual Conference of the Royal Economic Society (Belfast) for their comments.

* Address correspondence to: Leonid V. Azarnert, National Research University Higher School of Economics, Department of Economics, Kantemirovskaya 3A, St Petersburg, 194100, Russia; e-mail: Leonid.Azarnert@gmail.com
} 


\section{Introduction}

By using a partial equilibrium OLG model, this paper discusses how the provision of public health spending affects fertility and private investment in children's education and health. I show that if public health services and private investment in children's education are complementary, then the provision of free health services lowers education investment and increases fertility. The novelty of the paper is introducing health into children's human capital accumulation function, while considering the public knowledge spillover effect.

A large empirical literature argues that improved health expands education and leads to better educational outcomes. See, for example, Alderman et al. (2001), Behrman and Rosenzweig (2004), Miguel and Kremer (2004), Bleakley (2007), Bleakley and Lange (2009), Oster et al. (2013), among many others. ${ }^{1}$ Positive causal effect running from increased education to better health has also been well established in a vast amount of research (e.g. Cutler and Lleras-Muney, 2010; Brunello et al., 2016; Strulik, 2018, where further references can be found).

Consistent with the historical relationship among longevity, education and percapita output, which have been increasing simultaneously in presently developed countries since the middle of the nineteenth century, numerous theoretical studies that explore transition from stagnation to growth argue that reductions in mortality and improvements in longevity spur investment in human capital and cause growth. See, for example, Ehrlich and Lui (1991), de la Croix and Licandro (1999, 2013), Kalemli-Ozcan et al. (2000), Kalimli-Ozcan (2002), Boucekkinie et al. (2002, 2003), Blackburn and Cipriani (2002), Lagerloff (2003), Weisdorf (2004), Chakraborty (2004), Soares (2005), Cervellati and Sunde (2005, 2011, 2015), Castello-Climent and Domenech (2008), Tamura (2006), Chen (2010), Strulik and Weisdorf (2014), among many others. ${ }^{2}$

\footnotetext{
${ }^{1}$ Some additional references to the copious literature on the causes and consequences of poor health in childhood can be found, for instance, in Aksan (2014) and Madsen (2018).

${ }^{2}$ It has however been argued that, if child mortality is realized before education starts, an exogenous decline in child mortality can lead to a decline in education, because it lowers the cost of rearing surviving children, which makes child quantity more attractive relative to quality (Azarnert 2006; Fioroni 2010). Hazan and Zoabi (2006) argue that greater longevity of children increases not only the returns to education, but also the returns to the number of children as each child lives longer, thereby mitigating the positive effect of longevity on education. Strulik and Werner (2016) suggest that it is healthy life expectancy rather than life expectancy as such that promotes education and economic growth.
} 
In a related strand of the literature, adult mortality has been endogenized by considering how public health expenditure (Chakraborty, 2004; Fanti and Gori, 2014; Fanti et al., 2019), private health expenditure (Chakraborty and Das, 2005), or both (Bhattacharya and Qiao, 2007) affect an individual's survival probability. In Blackburn and Cipriani (2002), education is the main determinant of the probability of adult survival. Cigno (1998), Blackburn and Cipriani (1998) and Strulik (2004) endogenized child survival by putting the offspring's mortality subject to parental choice. In Weisdorf (2004), child mortality is inversely related to parental living standards. In Azarnert (2006), at low levels of income, the offspring's survival probability increases with the parental levels of human capital. In Strulik (2008), child survival depends on geographic location, the average income per capita in the economy and parental expenditure per child. In Tamura (2006), young adult mortality is negatively related to an individual's own level of human capital, the average level of human capital in the society and the maximum level of human capital in the world. Similarly, in Tamura and Cuberes (2019), human capital investment raises the likelihood that a young adult survives to adulthood. In Castello-Clement and Domenech (2008), adult individuals' survival probability depends on the human capital of their parents. In Futagami and Konishi (2019), the probability of survival from adulthood to old age depends on the wage rate.

Researchers have also studied the effect of health on investment in education in a number of theoretical models, in which health was separated from longevity or probability of survival. Hazan and Zoabi (2006), whose work is closest in spirit to the model presented in this paper, assume that health joints education as an input in the production of human capital. In Aksan and Chakraborty $(2013,2014)$, the major working assumption is that children can belong to a healthy or an unhealthy type, and that the return to investment in a healthy child's human capital is higher than the return to investment in an unhealthy child's human capital. Strulik and Werner (2016) assume that better health increases productivity and amplifies the return to education. ${ }^{3}$

\footnotetext{
${ }^{3}$ In a related study, Varvarigos and Zakaria (2013) assume that better health in old age increases utility from consumption, which motivates investment in health. They however do not consider investment in education. Strulik (2017) integrates health in the utility function to suggest a novel explanation for a humpshaped age-consumption profile.
} 
This paper expands the literature on investments in education and human capital accumulation in the direction of public interventions in the production of health capital. The analysis is performed in a growth model with endogenous fertility in the tradition of Galor and Tsiddon (1997) building on Azarnert (2010a), where the effect of free education on fertility, private educational investment and human capital accumulation was considered. ${ }^{4}$ In this model, the usual parental trade-off between the quantity and quality of their offspring is augmented with an additional separate factor that affects the children's quality, which is health. This allows us to analyze how public policy interventions in the production of children's health capital affect parental optimal decisions with respect to the number of children and investment in both the children's health and education, which is new to the literature.

In this paper, I assume that public health services are financed by taxes levied outside of the economic environment that is being considered ${ }^{5}$ and thereby are free to families. This allows us to abstract from the effect of taxation on individuals' decisions with respect to the optimal investments in quantity and quality of their offspring and concentrate on the pure effect of the provision of free public health services. ${ }^{6}$ This assumption is consistent with reality, in particular, in presently developing countries, where public health services for children are usually financed with considerable aid from foreign donors. Immunization of children against infectious and parasitic diseases is a good example of public health intervention that is free for households.

I incorporate health into the model by assuming that it joints education as an additional input in the production of human capital. I assume that the production function

\footnotetext{
${ }^{4}$ For surveys of the literature on endogenous fertility and growth, see Galor $(2011,2012)$. Other works in this context that the present model is connected to include Galor and Moav (2000), Moav (2005), Galor and Mountford (2008) and Azarnert (2016, 2010d, 2019). Tamura et al. (2016) and Tamura and Simon (2017) produce demographic transitions that fit black and white fertility and schooling at the US states level and fertility and schooling at the country level for 21 countries, respectively. Cf. also Day (2016) where a market for child care is incorporated.

${ }^{5}$ In this case, the particular type of tax levied to finance public health services is irrelevant for the analysis.

${ }^{6}$ The disincentive effect of taxation that reduces the net return to investment in human capital on human capital accumulation has long been well recognized in the literature. Thus, for example, Banerjee (2004) argues that a proportional tax on human capital reduces human capital investment even if the proceeds are then redistributed as a lump-sum educational subsidy. Palivos and Scotese (1996) argue that, when services to children are financed by taxation, the equilibrium outcome is biased away from the socially preferred result toward higher fertility rate and lower economic growth, because each household internalizes the benefits, but not the costs of the tax-financed services. The negative effect of taxation and income
} 
exhibits positive and decreasing marginal product in health and education and that the two inputs are complements. I also assume that public and private health investments are substitutes. Given the substitutability between the two health inputs, a disincentive effect of free public health services on the parental own investment in their children's health is not surprising. The major contribution of the present paper in this context is to show that, if parents derive utility from both quantity and quality of their offspring, while health and formal education are complementary in the production of human capital, even in the absence of a negative effect of taxation on the incentives to invest in human capital, the provision of free public health services not only crowds out parental own investment in their children's health, but also reduces their investment in the children's education and increases fertility. This result is opposite of the outcome in a framework with exogenous fertility where a reallocation of parental resources from quality to quantity of the offspring is impossible and therefore the provision of free public health services reduces private investment in children's health, but increases investment in schooling.

The present analysis shows that the effect of public policy intervention in the provision of free health services depends on the society's level of human capital as well as on the distribution of human capital across individuals within society. Thus, in a less developed economy, in which the majority of individuals are characterized by relatively low levels of human capital and do not invest in health and education of their offspring, the positive effect of the provision of free health services is strong enough to outweigh its disincentive effect on the small fraction of relatively highly skilled agents. ${ }^{7}$ In contrast, in a more developed economy, in which highly skilled individuals are numerous enough, a disincentive effect of free health services on parents who invest in health and education of their children may dominate its positive effect on the offspring of the relatively low skilled parents. I analyze the overall society-wide effect of public policy intervention in the production of health capital and derive a condition that determines precisely whether public provision of free health services increases or decreases the average level of human capital in the society.

redistribution on the incentive to invest in human capital is shown also in Azarnert (2004, 2010c), where further references can be found. 
The present analysis suggests that, once the necessarily high level of human capital in the society is achieved, to enhance human capital accumulation, an appropriate public health policy should substitute away from the provision of free health services and concentrate on improvements in the productivity of private health investment. Such policy can be implemented, for example, in the form of subsidizing the costs of private health care, gyms and sports clubs for children and adolescents. Given the complementarity between health and formal education in the production of human capital, improvements in the productivity of private investment in health will increase the attractiveness of investment in both children's health and education and reduce fertility.

\section{The Basic Structure of the Model}

Consider an overlapping-generations economy, in which activity extends over an infinite discrete time. In every period, the economy produces a single homogenous good using a constant-returns-to-scale technology with human capital as the only input. In each generation, agents live for two periods: childhood and adulthood. During childhood, individuals acquire human and health capital. During adulthood, they work, become parents and bring up their offspring. As parents, adult individuals allocate a positive fraction of their time to feeding and raising their children and may invest in their offspring's education and health.

\subsection{The Formation of Human Capital}

In period $t$, an adult is characterized by a skill level $h_{t}$ that is distributed according to the cumulative density function $F_{t}(\cdot)$ over the strictly positive support $\left[h_{t}^{\min }, h_{t}^{\max }\right]$. In each period of life, individuals are endowed with one unit of time. In the first period, children devote their entire time to the acquisition of human and health capital. The acquired human capital increases if their time investment is supplemented with real resources invested in their education.

\footnotetext{
7 This result is in line with the findings of previous studies, such as, for example, Chakraborty (2004), Bhattacharya and Qiao (2007) and Varvarigos and Zakaria (2013), that neglect the possible disincentive effect of the public provision of free health services.
} 
The human capital level of a child, who becomes an adult in period $t+1$, depends on the parental real expenditure on the child's education, $e_{t}$, on the average level of human capital of all adult individuals in economy in period $t$, which is defined as

$\bar{h}_{t}=\int h_{t} d F_{t}(h)$, and on his health capital, $R_{t+1}$, according to the human capital production function or learning technology described by

$$
h_{t+1}=\Theta\left(e_{t}, \bar{h}_{t}, R_{t+1}\right) \text {. }
$$

This learning technology captures an external spillover effect that arises from the average society's level of human capital, $\bar{h}_{t}$. Such formulation is consistent with the socalled global or atmospheric externality, which implies that an increase in the average level of human capital in the society as a whole increases the rate of return to investment in human capital for the children's generation. First introduced by Tamura (1991), the assumption that the average level of human capital in society is an input in the production of human capital for each individual became common in the literature. This externality has been utilized, e.g., by Tamura (1996), Galor and Tsiddon (1997), Morand (1999), Viaene and Zilcha (2002, 2009), de la Croix and Doepke (2004), Azarnert (2008, 2014, 2018), and Aksan and Chakraborty (2014), among many others.

The novelty of the present work relative to the aforementioned studies is that in this model better health increases the productivity of investment in human capital. This assumption is in line with Hazan and Zoabi (2006), who, on the other hand, abstract from the spillover effect of the society's level of human capital in the production of an individual's human capital and heterogeneity across individuals.

A particular form of human capital production function is specified below in equation (7).

\subsection{The Formation of Health Capital}

Health capital is assumed to be produced through private and public channels, which are easily distinguishable. In addition to the exogenously given public health services equal for each child and provided for free to the families, parents may decide to commit some fraction of their resources to private investment in health of their children in order to increase their levels of health capital. However, even in the absence of any real health 
expenditures, children obtain some basic level of health. The health capital level of a child, who becomes an adult in period $t+1$, depends on the level of public health expenditure per child, $\rho$, the parental real expenditure on the child's health, $r_{t}$, and on the basic (natural) level of health equal for each child, according to the health capital production function described by

$$
R_{t+1}=\Psi\left(\underline{\rho}, \rho, r_{t}\right)=\xi(\underline{\rho}) \psi\left(\rho, r_{t}\right) .
$$

This health capital production function is required to satisfy the following set of assumptions:

Assumptions. $\forall\left(\rho, r_{t}\right) \in \mathfrak{R}_{+}^{2}$

A1.1. $\psi: \mathfrak{R}_{+}^{2} \rightarrow \mathfrak{R}_{+} ; \psi$ is twice differentiable;

A1.2. $\mathrm{D} \psi\left(\rho, r_{t}\right)>0$;

A1.3. $\psi_{12}\left(\rho, r_{t}\right)<0$ and $\psi_{j j}\left(\rho, r_{t}\right)<0, j=1,2$;

A1.4. $\forall \underline{\rho}>0, \Psi(\underline{\rho}, 0,0)>0$.

These assumptions have the following implications:

- A child's level of health capital is an increasing function of the level of public provision of health services and the level of private investment in the child's health (i.e., $\psi_{1}(\cdot, \cdot)>0$ and $\left.\psi_{2}(\cdot, \cdot)>0\right)$.

- Public and private health inputs are substitutes and are characterized by diminishing returns (i.e., $\psi_{12}\left(\rho, r_{t}\right)<0$ and $\left.\psi_{j j}\left(\rho, r_{t}\right)<0, j=1,2\right)$.

- Even in the absence of public health services, children, whose parents do not invest in their health, benefit from the basic (natural) level of health (i.e., $\forall \underline{\rho}>0, \Psi(\underline{\rho}, 0,0)>0)$. A particular form of health capital production function is specified below in equation (8).

\subsection{The Optimization of Parents}

Agents derive utility from their own consumption in adulthood and from the total future income of their children. The utility function of an individual born at time $t-1$ is therefore

$$
U_{t}=(1-\beta) \log C_{t}+\beta \log \left(I_{t+1}^{N}\right),
$$


where $C_{t}$ is an individual's own consumption, $I_{t+1}^{N}$ is the future income of that individual's offspring and $\beta \in(0,1)$ captures the relative weight given to children. ${ }^{8}$

In every period $t$, adult individuals are endowed with one unit of time, which they allocate between childbearing and labor force participation. The cost of feeding and raising children is measured in terms of work time foregone at $\delta$ per child. The cost of acquiring human and health capital is measured in units of the wage per efficiency unit of labor, $w$. The wage per efficiency unit of labor, $w$, is fixed over time, as follows from, for instance, the assumption of a constant return to scale (CRS) technology with a single factor of production.

To maximize utility, an adult individual simultaneously chooses a current consumption, $C_{t}$, the number of children, $N_{t}$, and may invest $e_{t}$ units of $w$ in each child's education and $r_{t}$ units of $w$ in each child's health subject to the following budget constraint:

$$
C_{t}+w\left(\delta h_{t}+r_{t}+e_{t}\right) N_{t} \leq w h_{t} .
$$

The right-hand side of equation (4) represents an adult's income, which is allocated between consumption and the total cost of rearing children.

The total future income of that individual's offspring is:

$$
I_{t+1}^{N}=N_{t} h_{t+1} w
$$

\subsection{Choice of Fertility and Investment in the Offspring's Health and Human Capital}

From optimization, an adult's consumption is

$$
C_{t}=(1-\beta) h_{t} w .
$$

That is, a fraction $1-\beta$ of an adult's income is devoted to consumption and hence a fraction $\beta$ is devoted to childrearing.

To characterize optimal choices of fertility and investment in the offspring's education and health, I postulate the following human capital production function that

\footnotetext{
8 In the utility function postulated by Galor and Moav (2002), individuals differ with respect to the relative weight given to the quality of their children. In the utility function used in Azarnert (2010b), where the choice is between giving birth to one child per parent or remaining childless, individuals differ with respect to the weight given to the child.
} 
implies that better health increases productivity of the investment in human capital and amplifies the return to education:

$$
h_{t+1}=\left(\mu+e_{t}\right)^{\gamma} \bar{h}_{t}^{1-\gamma-\sigma} R_{t+1} \text {, where } \mu>0,0<\gamma<1,0<\sigma<1 \text { and } \gamma+\sigma<1 \text {, }
$$

and $\mu$ is associated with the spillover effect of public knowledge that all children benefit from regardless of parental investment in their education, as has been discussed in Section 2.1 above.

To focus on the investment in health, I postulate the particular health capital production function that captures the major difference between the two sources of health capital. On the one hand, regardless of their parents' wealth or skill levels, free public services provide the same level of health for all children. On the other hand, for any given level of free public health services, additional private health expenditure is subject to the family's choice. The function also implies that in the absence of any real investment in their health (public or private), children obtain some basic (natural) level of health, $\underline{\rho}^{\sigma}$ :

$$
R_{t+1}=\left(\underline{\rho}+\rho+\omega r_{t}\right)^{\sigma}, \text { where } \underline{\rho}>0, \rho \geq 0, \omega>0,0<\sigma<1,
$$

$\rho$ measures the level of public health expenditure financed by "outside of the model" per child and $\omega$ corresponds to the relative efficiency of private health capital investment, $r_{t}$.

Given the health and human capital production functions, as postulated in equations (7) and (8) respectively, the existence of a non-corner choice with respect to investment in human capital implies the necessary condition that

$$
h_{t}>\hat{h}_{1}=\left(\frac{\mu(1-\sigma)}{\gamma}+\frac{\rho+\rho}{\omega}\right) / \delta \text {. }
$$

Similarly, a non-corner solution with respect to investment in health capital requires that

$$
h_{t}>\hat{h}_{2}=\left(\frac{(\rho+\rho)(1-\gamma)}{\sigma \omega}+\mu\right) / \delta \text {. }
$$

Obviously, the thresholds (9) and (10) are increasing with the amount of public health expenditure $(\rho)$ and decreasing with the relative efficiency of private health investment $(\omega)$. 
According to equations (9) and (10), there potentially exist the following four types of parents in the economy:

1. Parents with human capital below the lowest threshold, $h_{t}<\min \left\{\hat{h}_{1}, \hat{h}_{2}\right\}$ who choose not to invest privately in health or human capital of their offspring $\left(r_{t}=0, e_{t}=0\right)$. According to equation (8), for any non-negative level of public health subsidy $(\rho \geq 0)$, their children receive $(\underline{\rho}+\rho)^{\sigma}$ units of health capital, when they become adults

$$
R_{t+1}=(\underline{\rho}+\rho)^{\sigma} .
$$

Therefore, given the level of health, as determined in equation (11), according to equation (7), they receive

$$
h_{t+1}=\mu^{\gamma}(\underline{\rho}+\rho)^{\sigma} \bar{h}_{t}^{1-\gamma-\sigma} .
$$

As no resources are allocated to children's health and education, the desired number of children is calculated simply by dividing the parent's income after consumption by the quantity cost per child

$$
N_{t}=\frac{\beta}{\delta}
$$

2. Parents with human capital above the highest threshold, $h_{t}>\max \left\{\hat{h}_{1}, \hat{h}_{2}\right\}$ who choose to invest in both health and human capital of their offspring $\left(r_{t}>0, e_{t}>0\right)$. For such parents, the optimal choices of investment in children's health and human capital are as follows

$$
r_{t}=\frac{\sigma\left(\delta h_{t}-\mu\right)-((\underline{\rho}+\rho)(1-\gamma) / \omega)}{1-\gamma-\sigma}
$$

and

$$
e_{t}=\frac{\gamma\left(\delta h_{t}-((\underline{\rho}+\rho) / \omega)\right)-\mu(1-\sigma)}{1-\gamma-\sigma},
$$

so that, according to equations (8) and (7), their levels of health and human capital are

$$
R_{t+1}=\left(\frac{\sigma\left(\omega\left(\delta h_{t}-\mu\right)-(\underline{\rho}+\rho)\right)}{1-\gamma-\sigma}\right)^{\sigma}
$$

and 


$$
h_{t+1}=\left(\frac{\gamma\left(\delta h_{t}-((\underline{\rho}+\rho) / \omega)-\mu\right)}{1-\gamma-\sigma}\right)^{\gamma}\left(\frac{\sigma\left(\omega\left(\delta h_{t}-\mu\right)-(\underline{\rho}+\rho)\right)}{1-\gamma-\sigma}\right)^{\sigma} \bar{h}_{t}^{1-\gamma-\sigma} .
$$

Given the amount of resources allocated to children's health and education, the desired fertility is

$$
N_{t}=\frac{\beta(1-\gamma-\sigma)}{\delta-\frac{\mu}{h_{t}}-\frac{\rho+\rho}{\omega h_{t}}} .
$$

Equation (14) shows that the optimal choice of investment in the offspring's health and, hence, the children's health capital level (Eq. 16) is positively related to the parent's human capital, although parental human capital does not enter the health capital production function directly. Equations (15) and (17) show the positive relationship between the parental and the offspring's levels of human capital. Equation (18) displays the traditional negative relationship between the parental level of human capital and the choice of fertility.

The above equations also demonstrate that public health spending, associated with the parameter $\rho$, crowds out not only parental private expenditure on their offspring's health $\left(r_{t}\right)$, but also their expenditure on the offspring's education $\left(e_{t}\right)$. In contrast, an increase in the relative efficiency of parental private health investment $(\omega)$ has the opposite effect, and is associated with an increase in the attractiveness of parental investment in both their children's health and education.

Furthermore, if $\rho \neq \frac{\mu \sigma \omega}{\gamma}-\underline{\rho}, \hat{h}_{1} \neq \hat{h}_{2}$ and, hence, $\min \left\{\hat{h}_{1}, \hat{h}_{2}\right\} \neq \max \left\{\hat{h}_{1}, \hat{h}_{2}\right\}$, parental human capital levels can be higher than the lower threshold, but lower than the higher threshold. ${ }^{9}$ In such a case, in the economy can exist one of the following two types of parents. If $\rho>\frac{\mu \sigma \omega}{\gamma}-\underline{\rho}, \min \left\{\hat{h}_{1}, \hat{h}_{2}\right\}=\hat{h}_{1}$ and $\max \left\{\hat{h}_{1}, \hat{h}_{2}\right\}=\hat{h}_{2}$. In this case,

3. Parents with human capital above the threshold $\hat{h}_{1}$, but below the threshold $\hat{h}_{2}$, $\hat{h}_{1}<h_{t}<\hat{h}_{2}$, choose to invest only in their offspring's human capital $\left(r_{t}=0, e_{t}>0\right)$. For

9 If $\rho=(\mu \sigma \omega / \gamma)-\underline{\rho}, \min \left\{\hat{h}_{1}, \hat{h}_{2}\right\}=\max \left\{\hat{h}_{1}, \hat{h}_{2}\right\}$ and, hence, $\hat{h}_{1}=\hat{h}_{2}$. In such a case, there exist only parents of types 1 and 2 . 
such parents, who do not invest in their children's health, the optimal investment in the offspring's human capital is

$$
e_{t}=\frac{\gamma \delta h_{t}-\mu}{1-\gamma}
$$

and, hence, the desired fertility is

$$
N_{t}=\frac{\beta(1-\gamma)}{\delta-\left(\mu / h_{t}\right)}
$$

Therefore, the resulting health and human capital levels per child are, respectively

$$
R_{t+1}=(\underline{\rho}+\rho)^{\sigma}
$$

and

$$
h_{t+1}=\left(\frac{\gamma}{1-\gamma}\left(\delta h_{t}-\mu\right)\right)^{\gamma}(\underline{\rho}+\rho)^{\sigma} \bar{h}_{t}^{1-\gamma-\sigma} .
$$

If, however, $\rho<\frac{\mu \sigma \omega}{\gamma}-\underline{\rho}, \min \left\{\hat{h}_{1}, \hat{h}_{2}\right\}=\hat{h}_{2}$ and $\max \left\{\hat{h}_{1}, \hat{h}_{2}\right\}=\hat{h}_{1}$. In this case,

4. Parents with human capital above the threshold $\hat{h}_{2}$, but below the threshold $\hat{h}_{1}$, $\hat{h}_{2}<h_{t}<\hat{h}_{1}$, choose to invest only in their offspring's health capital $\left(r_{t}>0, e_{t}=0\right)$. For such parents, who do not invest in their children's education, the optimal investment in the offspring's health capital is

$$
r_{t}=\frac{\sigma \delta h_{t}-((\underline{\rho}+\rho) / \omega)}{1-\sigma}
$$

and therefore the optimal fertility is

$$
N_{t}=\frac{\beta(1-\sigma)}{\delta-\frac{\rho+\rho}{\omega h_{t}}},
$$

with the resulting health and human capital levels per child

$$
R_{t+1}=\left(\frac{\sigma}{1-\sigma}\left(\omega \delta h_{t}-(\underline{\rho}+\rho)\right)\right)^{\sigma}
$$

and

$$
h_{t+1}=\mu^{\gamma}\left(\frac{\sigma}{1-\sigma}\left(\omega \delta h_{t}-(\underline{\rho}+\rho)\right)\right)^{\sigma} \bar{h}_{t}^{1-\gamma-\sigma} .
$$


The following proposition summarizes the main result of this section concerning the effect of free public health services (as captured by a given parameter $\rho$ ) on fertility and children's health and human capital.

Proposition 1: The availability of free public health services $(\rho>0)$

(1) Increases the threshold levels of human capital, below which parents do not invest in health $\left(\hat{h}_{1}\right)$ or human $\left(\hat{h}_{2}\right)$ capital of their children.

(2) Decreases parental investment and the resulting health and human capital levels per child among children whose parents invest in the offspring's health and increases health and human capital levels per child among children whose parents do not invest in the offspring's health.

(3) Increases fertility among parents who invest in the offspring's health and do not affect fertility among parents who do not invest in the offspring's health.

Moreover, if $\rho<\frac{\mu \sigma \omega}{\gamma}-\underline{\rho}$ and, hence, $\min \left\{\hat{h}_{1}, \hat{h}_{2}\right\}=\hat{h}_{2}$ and $\max \left\{\hat{h}_{1}, \hat{h}_{2}\right\}=\hat{h}_{1}$, an increase in the amount of public health expenditure (as captured by an increase in the parameter $\rho$ ) can also change the order of the thresholds and transform the highest threshold into the lowest and vice versa. ${ }^{10}$ In this case, type 3 of parents who invest only in their offspring's health ceases to exist in the economy and there appears type 4 of parents who invest only in their children's education.

\subsection{Human Capital Accumulation Dynamics}

This section examines the effect of public policy interventions in the provision of health capital on the society's average level of human capital at different stages of economic development.

Given the results of the previous section, as summarized in Proposition 1, it is intuitively clear that the effect of public policy intervention in the provision of free health

10 Technically, this change happens if, as a result of an increase in the parameter $\rho$, inequality $\rho<(\mu \sigma \omega / \gamma)-\underline{\rho}$ changes its sign and becomes $\rho>(\mu \sigma \omega / \gamma)-\underline{\rho}$. 
services depends on the society's level of human capital as well as on the distribution of human capital levels of individuals within society. Thus, in a less developed economy, in which the majority of individuals are characterized by relatively low levels of human capital below the thresholds and therefore do not invest privately in health and education of their offspring, the positive effect of the provision of free health services is strong enough to outweigh its disincentive effect on the small minority of relatively highly skilled agents. In contrast, in a more developed economy, in which individuals with human capital levels above the thresholds are numerous enough, a disincentive effect of free health services for parents with human capital above the thresholds may dominate its positive effect on the offspring of parents with human capital below the thresholds.

Comparing the level of human capital when free public health services are provided $\left(\bar{h}_{t+1}^{\rho>0}\right)$ to that in the absence of such services $\left(\bar{h}_{t+1}^{\rho=0}\right)$, as shown in equation (A2) in Appendix A, allows us to determine precisely whether public provision of free health services increases or decreases the average level of the society's human capital. Thus, if $\bar{h}_{t+1}^{\rho>0}>\bar{h}_{t+1}^{\rho=0}$, free health services increase the economy's average level of human capital. In contrast, if $\bar{h}_{t+1}^{\rho>0}<\bar{h}_{t+1}^{\rho=0}$, the average level of human capital in the economy is higher in the absence of health services provided for free to families. The economy therefore evolves along one of the following three cases.

1. A less advanced economy. In this case, if the initial fraction of the skilled and their human capital levels are not high enough, the positive contribution of the skilled who invest in the quality of their children to the society's average human capital may be diluted by the growing number of the unskilled. ${ }^{11}$ As a consequence, stemming from the global externality in the production of human capital, the society's average human capital ceases to grow. The economy is thus locked in a low-equilibrium poverty trap with increasing population and decreasing per capita human capital levels, so that for all

\footnotetext{
${ }^{11}$ Tamura (1996) first identified the possibility of dilution effects from differential fertility in human capital spillover models. By construction of this model, equation (A2) in Appendix A does not imply nondecreasing per capita human capital levels over time, because children, whose parents do not invest in their quality, may receive less than the per capita human capital level of the previous period, when they become adults.
} 
$j>0, \bar{h}_{t+j}^{\rho=0}<\bar{h}_{t} \cdot{ }^{12}$ At this stage of development, the provision of free access to public health services $(\rho>0)$ that could be financed with a considerable aid from foreign donors in the case of a less developed country or from a central government in the case of a poorer community can change the path of human capital accumulation and pull the economy out of a poverty trap and toward a path of increasing per capita human capital levels, so that $\bar{h}_{t+1}^{\rho>0}>\bar{h}_{t}>\bar{h}_{t+1}^{\rho=0} \cdot{ }^{13}$

2. A moderately advanced economy. In this case, if the initial fraction of skilled parents and their human capital levels are relatively high, the economy evolves along a path of strictly increasing human capital levels, so that for all $j>0, \bar{h}_{t+j}^{\rho=0}>\bar{h}_{t}$. However, at this stage of development, the positive effect of public health spending on the poor still dominates and therefore the provision of free health services may stimulate human capital accumulation and spur growth, so that $\bar{h}_{t+1}^{\rho>0}>\bar{h}_{t+1}^{\rho=0}>\bar{h}_{t}$.

3. A more advanced economy. At this stage, the counter-incentive effect on the skilled is dominant and therefore the society-wide effect of free health services reverses and becomes negative, so that $\bar{h}_{t+1}^{\rho=0}>\bar{h}_{t+1}^{\rho>0}>\bar{h}_{t}$.

An illustrative numerical example is provided in Appendix B below. The effect of free health services on the average level of health capital in the economy can be established in a similar manner using equation (A3) in Appendix C.

The present analysis thus suggests that once the necessarily high level of individual human capital in the society is achieved, a decrease in the public spending on the provision of free health services, associated with a reduction in the parameter $\rho$, may increase the society's average human and health capital. From this point onward, to enhance human capital accumulation, an appropriate public health policy should concentrate on improvements in the productivity of private health investments, as modeled here by an increase in the parameter $\omega$. Such policy can be implemented, for example, in the form of subsidizing the costs of private health care and financing gyms

\footnotetext{
${ }^{12}$ To rule out the possibility that in period $t+n$ human capital will ultimately converge to $\bar{h}_{t+n}=0$, the human capital production function (7) could be reformulated as $h_{t+1}=\max \left\{h^{\min },\left(\mu+e_{t}\right)^{\gamma} \bar{h}_{t}^{1-\gamma-\sigma} R_{t+1}\right\}$.

${ }^{13}$ This result echoes the famous finding by Chakraborty (2004) who considered public health investment as a prerequisite for sustained economic growth.
} 
and sports clubs for children and adolescents. Along with the direct positive effect on parental private investment in their children's health, such policy will also increase the attractiveness of investment in children's education and reduce fertility.

\section{Conclusion}

This article analyzes the effect of public policy intervention in the production of health capital on fertility, private investment in children's health and education and human capital accumulation. I have used a growth model with endogenous fertility, in which the usual parental trade-off between the quantity and quality of their children is augmented with an additional separate factor that affects the children's quality, which is health. I analyze the overall society-wide effect of public policy intervention in the production of health capital and derive a condition that determines precisely whether public provision of free health services increases or decreases the average level of human capital in the society. The analysis also suggests that, once the necessarily high level of human capital in the society is achieved, to enhance human capital accumulation, an appropriate public health policy should substitute away from the provision of free health services and concentrate on improvements in the productivity of private health investment.

\section{Appendix A. The average level of human capital}

The average human capital level in period $t+1$ is defined as

$$
\bar{h}_{t+1} \equiv \int h_{t+1} d F_{t+1}(h)=\int N_{t} h_{t+1} d F_{t}(h) / \int N_{t} d F_{t}(h) \text {. }
$$

Distinguishing parents of each type and given the number of children and the levels of human and health capital investment among the four types of agents, as determined in Section 2.5, for any nonnegative level of free public health services $(\rho \geq 0)$, the average human capital level in period $t+1$ is ${ }^{14}$

\footnotetext{
${ }^{14}$ Note however that, as shown in Section 2.5, if $\rho \neq(\mu \sigma \omega / \gamma)-\underline{\rho}$, parents of type 3 and 4 cannot exist simultaneously. Therefore, either the third or the fourth element in the numerator and the denominator in equation (A2) should equal zero.
} 


$$
\begin{aligned}
& \bar{h}_{t+1}^{\rho \geq 0}=\bar{h}_{t}^{1-\gamma-\sigma}\left[\mu^{\gamma}(\underline{\rho}+\rho)^{\sigma} \int_{h_{t}<\min \left\{\hat{h}_{1}, \hat{h}_{2}\right\}}\left(\delta\left(1-\frac{\hat{h}_{1}}{h_{t}}\right)+\frac{(\mu(1-\sigma) / \gamma)+((\underline{\rho}+\rho) / \omega)}{h_{t}}\right)^{-1} d F_{t}\right. \\
& +\left(\frac{\gamma}{1-\gamma-\sigma}\right)^{\gamma}\left(\frac{\sigma}{1-\gamma-\sigma}\right)^{\sigma} \int_{h_{t}>\max \left\{\hat{h}_{1}, \hat{h}_{2}\right\}}\left(\delta h_{t}-\frac{(\underline{\rho}+\rho)}{\omega}-\mu\right)^{\gamma-1}\left(\omega\left(\delta h_{t}-\mu\right)-(\underline{\rho}+\rho)\right)^{\sigma} h_{t} d F_{t} \\
& +\left(\frac{\gamma}{1-\gamma}\right)^{\gamma} \underline{(\rho+\rho)^{\sigma}} \underset{\substack{\min \left\{\hat{h}_{1}, \hat{h}_{2}\right\}<h_{t}<\max \left\{\hat{h}_{1}, \hat{h}_{2}\right\} \\
\text { if } \rho>(\mu \sigma \omega / \gamma)-\underline{\rho}}}{\int}\left(\delta h_{t}-h_{t} d F_{t}\right.
\end{aligned}
$$

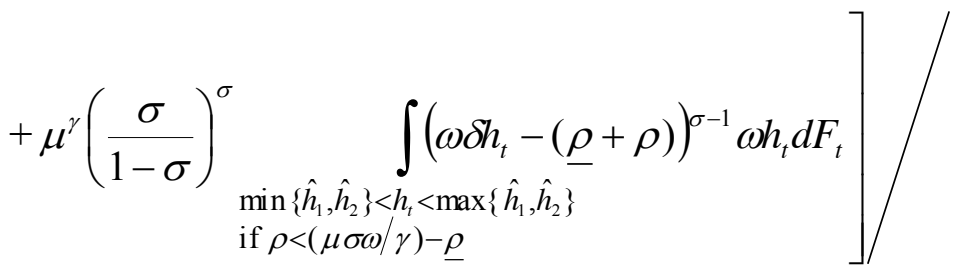

$$
\begin{aligned}
& {\left[\int_{h_{t}<\min \left\{\hat{h}_{1}, \hat{h}_{2}\right\}}\left(\delta\left(1-\frac{\hat{h}_{1}}{h_{t}}\right)+\frac{(\mu(1-\sigma) / \gamma)+((\underline{\rho}+\rho) / \omega)}{h_{t}}\right)^{-1} d F_{t}\right.} \\
& \left.+\int_{h_{t}>\max \left\{\hat{h}_{1}, \hat{h}_{2}\right\}}\left(\delta-(\underline{\rho}+\rho) / \omega h_{t}\right)-\left(\mu / h_{t}\right)\right)^{-1} d F_{t}
\end{aligned}
$$

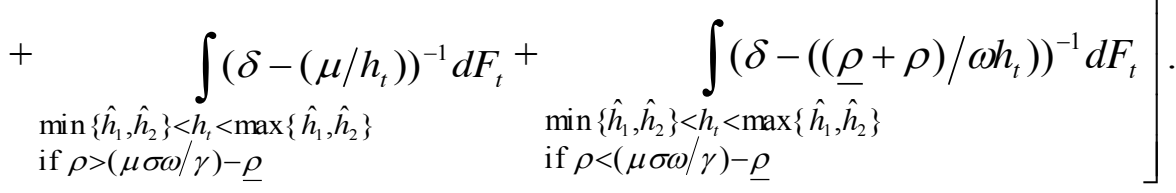

Appendix B. Numerical Example: The effect of the provision of free health services on human capital accumulation at different stages of development

To provide a numerical example, suppose that the parameters in the model are as follows: $\delta=0.2, \sigma=0.44, \gamma=0.5, \mu=1, \omega=1, \rho=0.1$, and $\rho=0.1$.

Also suppose that in period $t+1$ the economy can be either at a less advanced, a moderately advanced, or a more advanced stage of development. To distinguish between the three cases, suppose that, in the case of a less advanced economy (denoted by $j=L A$ ), the distribution of human capital in the economy is such that among 92 percent in the 
population human capital is distributed normally around $\bar{h}_{t}^{92 \%}=0.8$ with the lower bound $\bar{h}_{t}^{92 \% \text { min }}=0.1$ and the upper bound $\bar{h}_{t}^{92 \%, \max }=1.5$. Similarly, in the next 3 percent in the population human capital is distributed around $\bar{h}_{t}^{3 \%}=7.25$ with $\left.\left.\bar{h}_{t}^{3 \%} \in\right] 1.5,13\right]$, while in the highest 5 percent in the population $\bar{h}_{t}^{5 \%}=20$ with $\left.\left.\bar{h}_{t}^{5 \%} \in\right] 13,27\right]$. In the case of a moderately advanced economy (denoted by $j=\operatorname{ModA}$ ), the distribution of human capital in the economy is such that among 77 percent in the population human capital is distributed normally around $\bar{h}_{t}^{77 \%}=0.8$ with the lower bound $\bar{h}_{t}^{77 \%, \text { min }}=0.1$ and the upper bound $\bar{h}_{t}^{77 \% \text {,max }}=1.5$, in the next 3 percent in the population human capital is distributed around $\bar{h}_{t}^{3 \%}=7.25$ with $\left.\left.\bar{h}_{t}^{3 \%} \in\right] 1.5,13\right]$, and in the highest 20 percent in the population $\bar{h}_{t}^{20 \%}=20$ with $\left.\left.\bar{h}_{t}^{20 \%} \in\right] 13,27\right]$. Finally, in the case of a more advanced economy (denoted by $j=M A$ ), the distribution of human capital is such that among 57 percent in the population the average level of human capital equals $\bar{h}_{t}^{57 \%}=0.8$ with $\left.\left.\bar{h}_{t}^{57 \%} \in\right] 0.1,1.5\right]$, in the next 3 percent in the population $\bar{h}_{t}^{3 \%}=7.25$ with $\left.\left.\bar{h}_{t}^{3 \%} \in\right] 1.5,13\right]$, and among 40 percent in the population $\bar{h}_{t}^{40 \%}=20$ with $\left.\left.\bar{h}_{t}^{40 \%} \in\right] 13,27\right]$. In all other respects, the economy at a lower level of development $(j=L A)$ is similar to the economies at a moderate $(j=\operatorname{Mod} A)$ and a higher levels of development $(j=M A)$. Therefore, with the distribution of human capital as above, at a less advanced stage of development, the average level of human capital in the economy is $\bar{h}_{t}^{L A}=1.95$, at a moderately advanced stage of development $\bar{h}_{t}^{\text {ModA }}=4.83$, and at a more advanced stage of development, the average level of human capital in the economy is $\bar{h}_{t}^{M A}=8.67$.

Using equations (9) and (10), regardless of the stage of development, in the absence of free health services $(\rho=0)$, the human capital thresholds are $\hat{h}_{1}^{\rho=0}=6.1$ and $\hat{h}_{2}^{\rho=0}=5.6$, while in the presence of free public health services $(\rho=0.1), \hat{h}_{1}^{\rho=0.1}=6.6$ and $\hat{h}_{2}^{\rho=0.1}=6.1$, respectively. Therefore, if $\rho=0$, parents with human capital levels below the lowest threshold, $\hat{h}_{2}^{\rho=0}=5.6$, will choose not to invest in the education and health of their offspring, while parents with human capital between the thresholds, 
$5.6<h_{t} \leq 6.1$, will invest only in their children's health and parents with human capital above the highest threshold, $\hat{h}_{1}^{\rho=0}=6.1$, will invest in both health and human capital of their children. Similarly, in all three cases, if $\rho=0.1$, parents with human capital below $\hat{h}_{1}^{\rho=0.1}=6.1$ will not invest in human and health capital of their children, parents with human capital $6.1<h_{t} \leq 6.6$ will invest only in their children's health and parents with human capital above $\hat{h}_{2}^{\rho=0.1}=6.6$ will invest in both.

Therefore, with $\bar{h}_{t}^{L A}=1.95$ and given the distribution of human capital in the population as in the case of a less advanced stage of development, equation (A2) yields that in period $t+1$, in the absence of free health services, the average level of human capital in the economy will be $\bar{h}_{t+1}^{L A, \rho=0}=1.88$, while in the presence of free health services, the average level of human capital in the economy will be $\bar{h}_{t+1}^{L A, \rho=0.1}=2.05$ $\left(\bar{h}_{t+1}^{\rho=0.1}>\bar{h}_{t}>\bar{h}_{t+1}^{\rho=0}\right)$. Following the same steps, with $\bar{h}_{t}^{\text {ModA }}=4.83$ and given the distribution of human capital in the population as in the case of a moderate stage of development, in period $t+1$, in the absence of free health services, the average level of human capital in the economy will be $\bar{h}_{t+1}^{\operatorname{ModA} \rho=0}=5.74$, while in the presence of free health services, the average level of human capital in the economy will be $\bar{h}_{t+1}^{L A, \rho=0.1}=5.83$ $\left(\bar{h}_{t+1}^{\rho=0.1}>\bar{h}_{t+1}^{\rho=0}>\bar{h}_{t}\right)$. In contrast, with $\bar{h}_{t}^{M A}=8.67$ and given the distribution of human capital in the population as in the case of a more advanced stage of development, the effect of free health services on human capital accumulation reverses and becomes negative, so that in period $t+1, \bar{h}_{t+1}^{\rho=0}=10.54$ and $\bar{h}_{t+1}^{\rho=0.1}=10.47\left(\bar{h}_{t+1}^{\rho=0}>\bar{h}_{t+1}^{\rho=0.1}>\bar{h}_{t}\right)$.

\section{Appendix C. The average level of health capital}

Using the health capital production function (8) and following the same steps as in Appendix A, for any $\rho \geq 0$, the average level of health capital in the economy in period $t+1$ is

$$
\bar{R}_{t+1}^{\rho \geq 0}=\left[\underline{(\rho+\rho)^{\sigma}} \int_{h_{t}<\min \left\{\hat{h}_{1}, \hat{h}_{2}\right\}}\left(\delta\left(1-\frac{\hat{h}_{1}}{h_{t}}\right)+\frac{(\mu(1-\sigma) / \gamma)+((\underline{\rho}+\rho) / \omega)}{h_{t}}\right)^{-1} d F_{t}\right.
$$




$$
\begin{gathered}
+\left(\frac{\sigma}{1-\gamma-\sigma}\right)^{\sigma} \int_{h_{t}>\max \left\{\hat{h}_{1}, \hat{h}_{2}\right\}}\left(\omega\left(\delta h_{t}-\mu\right)-(\underline{\rho}+\rho)\right)^{\sigma-1} \omega h_{t} d F_{t} \\
+(\underline{\rho}+\rho)^{\sigma} \int_{\substack{\min \left\{\hat{h}_{1}, \hat{h}_{2}\right\}<h_{1}<\max \left\{\hat{h}_{1}, \hat{h}_{2}\right\} \\
\text { if } \rho>(\mu \sigma \omega / \gamma)-\underline{\rho}}}^{\int}\left(\delta-\left(\mu / h_{t}\right)\right)^{-1} d F
\end{gathered}
$$

$$
\begin{aligned}
& +\left(\frac{\sigma}{1-\sigma}\right)^{\sigma} \underset{\substack{\min \left\{\hat{h}_{1}, \hat{h}_{3}\right\}<h_{t}<\max \left\{\hat{h}_{1}, \hat{h}_{2}\right\} \\
\text { if } \rho<(\mu \sigma \omega / \gamma)-\underline{\rho}}}{\int}\left(\omega \delta h_{t}-(\rho+\rho) /\right. \\
& {\left[\int_{h_{t}<\min \left\{\hat{h}_{1}, \hat{h}_{2}\right\}}\left(\delta\left(1-\frac{\hat{h}_{1}}{h_{t}}\right)+\frac{(\mu(1-\sigma) / \gamma)+((\underline{\rho}+\rho) / \omega)}{h_{t}}\right)^{-1} d F_{t}\right.} \\
& \left.+\int_{h_{t}>\max \left\{\hat{h}_{1}, \hat{h}_{2}\right\}}\left(\delta-(\underline{\rho}+\rho) / \omega h_{t}\right)-\left(\mu / h_{t}\right)\right)^{-1} d F_{t}
\end{aligned}
$$

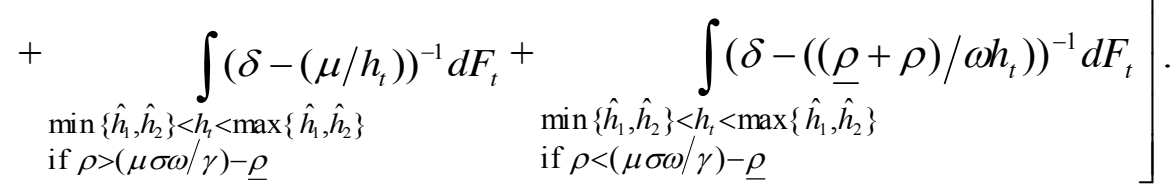

\section{References}

Aksan A-M (2014) Effects of childhood mortality and morbidity on the fertility transition in Sub-Sharan Africa. Population and Development Review 40, 311-329

Aksan A-M, Chakraborty S (2013) Childhood disease and the precautionary demand for children. Journal of Population Economics 26, 855-885

Aksan A-M, Chakraborty S (2014) Mortality versus morbidity in the demographic transition. European Economic Review 70, 470-492

Alderman H, Behrman JR, Lavy V, Menon R (2001) Child health and school enrollment a longitudinal analysis. Journal of Human Resources 36, 185-205

Azarnert LV (2004) Redistribution, fertility, and growth: the effect of the opportunities abroad. European Economic Review 48, 785-795 
Azarnert LV (2006) Child mortality, fertility and human capital accumulation. Journal of Population Economics 19, 285-297

Azarnert LV (2008) Foreign aid, fertility and human capital accumulation. Economica 75, $766-781$

Azarnert LV (2010a) Free education, fertility and human capital accumulation. Journal of Population Economics 23, 449-468

Azarnert LV (2010b) Après nous le déluge: fertility and the intensity of struggle against immigration. Journal of Population Economics 23, 1339-1349

Azarnert LV (2010c) Immigration, fertility, and human capital: a model of economic decline of the West. European Journal of Political Economy 26, 431-440

Azarnert LV (2010d) Juvenile imprisonment and human capital accumulation. Journal of Economic Inequality 8, 23-33

Azarnert LV (2014) Integrated public education, fertility and human capital. Education Economics 22, 166-180

Azarnert LV (2016) Transportation costs and the Great Divergence. Macroeconomic Dynamics 20, 214-228

Azarnert LV (2018) Refugee resettlement, redistribution and growth. European Journal of Political Economy 54, 89-98

Azarnert LV (2019) Migration, congestion and growth. Macroeconomic Dynamics 23, 3035-3064

Banerjee AB (2004) Educational policy and economics of the family. Journal of Development Economics 74, 3-32

Behrman JR, Rosenzweig MD (2004) Returns to birthweight. Review of Economics and Statistics 86, 586-601

Bhattacharya J, Qiao X (2007) Public and private expenditures on health in a growth model. Journal of Economic Dynamics and Control 31, 2519-2535

Blackburn K, Cipriani GP (1998) Endogenous fertility, mortality and growth. Journal of Population Economics 11, 517-534

Blackburn K, Cipriani GP (2002) A model of longevity, fertility and growth. Journal of Economic Dynamics and Control 26, 187-204 
Bleakley H (2007) Disease and development: evidence from hookworm eradication in the American South. Quarterly Journal of Economics 122, 73-117

Bleakley H, Lange F (2009) Chronic disease burden and the interaction of education, fertility and growth. Review of Economics and Statistics 91, 52-65

Brunello G, Fort M, Shneeweis N, Winter-Ebmer R (2016) The causal effect of education on health: what is the role of health behavior? Health Economics 25, 314-336

Bucekkine R, de la Croix D, Licandro O (2002) Vintage human capital, demographic trends, and endogenous growth. Journal of Economic Theory 104, 340-375

Bucekkine R, de la Croix D, Licandro O (2003) Early mortality decline at the dawn of modern growth. Scandinavian Journal of Economics 105, 401-418

Castello-Climent A, Domenech R (2008) Human capital inequality, life expectancy and economic growth. Economic Journal 118, 653-677

Cervellati M, Sunde U (2005) Human capital formation, life expectancy and process of economic development. American Economic Review 95, 1653-1672

Cervellati M, Sunde U (2011) Life expectancy and economic growth: the role of the demographic transition. Journal of Economic Growth 16, 99-133

Cervellati M, Sunde U (2015) The economic and demographic transition, mortality and comparative development. American Economic Journal: Macroeconomics 7, 189-225

Chakraborty S (2004) Endogenous lifetime and economic growth. Journal of Economic Theory 116, 119-137

Chakraborty S, Das M (2005) Mortality, human capital and persistent inequality. Journal of Economic Growth 10, 159-192

Chen H-J (2010) Life expectancy, fertility, and educational investment. Journal of Population Economics 23, 37-56

Cigno A (1998) Fertility decisions when infant survival is endogenous. Journal of Population Economics 11, 21-28

Cutler DM, Lleras-Muney A (2010) Understanding differences in health behavior by education. Journal of Health Economics 29, 1-28

Day C (2016) Fertility and economic growth: the role of workforce skill composition and child care prices. Oxford Economic Papers 68, 546-565 
de la Croix D, Licandro O (1999) Life expectancy and endogenous growth. Economic Letters 65, 255-263

de la Croix D, Licandro O (2013) The child is father of the man: implications for the demographic transition. Economic Journal 123, 236-261

de la Croix D, Doepke M (2004) Public versus private education when differential fertility matters. Journal of Development Economics 73, 607-629

Ehrlich I, Lui FT (1991) Intergenerational trade, longevity and economic growth. Journal of Political Economy 99, 1029-1059

Fanti L, Gori L (2014) Endogenous fertility, endogenous lifetime and economic growth: the role of child policies. Journal of Population Economics 27, 529-564

Fanti L, Gori L, Mammana C, Michetti E (2019) Inherited tastes and endogenous longevity. Macroeconomic Dynamics 23, 674-698

Fioroni T (2010) Child mortality and fertility under public vs private education. Journal of Population Economics 23, 73-97

Futagami K, Konishi K (2019) Rising longevity, fertility dynamics, and R\&D-based growth. Journal of Population Economics 32, 591-620

Galor O (2011) Unified Growth Theory. Princeton, NJ: Princeton University Press

Galor O (2012) The demographic transition: causes and consequences. Cleometrica 6, 128

Galor O, Moav O (2000) Ability based technological transition, wage inequality and economic growth. Quarterly Journal of Economics 115, 469-498

Galor O, Moav O (2002) Natural selection and the origin of economic growth. Quarterly Journal of Economics 117, 1133-1191

Galor O, Mountford A (2008) Trading population for productivity: theory and evidence. Review of Economic Studies 75, 1143-1179

Galor O, Tsiddon D (1997) The distribution of human capital and economic growth. Journal of Economic Growth 2, 93-124

Hazan M, Zoabi H (2006) Does longevity cause growth? A theoretical critique. Journal of Economic Growth 11, 363-376

Kalemli-Ozcan S, Ryder HE, Weil DN (2000) Mortality decline, human capital investment and economic growth. Journal of Development Economics 62, 1-23 
Kalemli-Ozcan S (2002) Does the mortality decline promote economic growth? Journal of Economic Growth 7, 411 - 439

Lagerloff NP (2003) From Malthus to modern growth: can epidemics explain the three regimes. International Economic Review 44, 755-777

Madsen JB (2018) Health-led growth since 1800. Macroeconomic Dynamics 22, 9611000

Miguel E, Kremer M (2004) Worms: identifying impact on education and health in the presence of treatment externalities. Econometrica 72, 159-217

Moav O (2005) Cheap children and the persistence of poverty. Economic Journal 115, $88-110$

Morand OF (1999) Endogenous fertility, income distribution, and growth. Journal of Economic Growth 4, 331-349

Oster E, Shoulson I, Dorsey ER (2013) Limited life expectancy, human capital and health investments. American Economic Review 103, 1977-2002

Palivos T, Scotese CA (1996) Fertility, growth and the financing of public education and health. Journal of Population Economics 9, 415-428

Soares RR (2005) Mortality reductions, educational attainment, and fertility choice. American Economic Review 95, 580-601

Strulik H (2004) Economic growth and stagnation with endogenous health and fertility. Journal of Population Economics 17, 433-453

Strulik H (2008) Geography, health, and the pace of demo-economic development. Journal of Development Economics 86, 61-75

Strulik H (2017) The health hump. Journal of Demographic Economics 83, 245-258

Strulik H (2018) The return to education in terms of wealth and health. Journal of the Economics of Ageing 12, 1-14

Strulik H, Weisdorf J (2014) How child costs and survival shaped the industrial revolution and the demographic transition. Macroeconomic Dynamics 18, 114-144

Strulik H, Werner K (2016) 50 is the new 30 - long-run trends of schooling and retirement explained by human aging. Journal of Economic Growth 21, 165-187

Tamura R (1991) Income convergence in an endogenous growth model. Journal of Political Economy 99, 522-540 
Tamura R (1996) From decay to growth: a demographic transition to economic growth. Journal of Economic Dynamics and Control 20, 1237-1261

Tamura R (2006) Human capital and economic development. Journal of Development Economics 79, 26-72

Tamura R, Simon C, Murphy KM (2016) Black and white fertility, differential baby booms: the value of equal education opportunity. Journal of Demographic Economics $82,27-109$

Tamura R, Simon C (2017) Secular fertility declines, baby booms, and economic growth: international evidence. Macroeconomic Dynamics 21, 1601-1672

Tamura R, Cuberes D (2019) Equilibrium and $A$-efficient fertility with increasing returns to population and endogenous mortality. Journal of Demographic Economics. Forthcoming

Varvarigos D, Zakaria IZ (2013) Endogenous fertility in a growth model with public and private health expenditures. Journal of Population Economics 26, 67-85

Viaene JM, Zilcha I (2002) Capital market integration, growth and income distribution. European Economic Review 46, 301-327

Viaene JM, Zilcha I (2009) Human capital and inequality dynamics. Economica 76, 760778

Weisdorf JL (2004) From stagnation to growth: revisiting three historical regimes. Journal of Population Economics 17, 455-472 